\title{
Heterogeneity of Cells Population and Secretome Profile of Differentiated Cells from E17 Rat Neural Progenitor Cells
}

\author{
Budiariati $\mathrm{V}^{1}$, Rinendyaputri $\mathrm{R}^{3}$, Noviantari $\mathrm{A}^{3}$, Budiono $\mathrm{D}^{1}$, Fahrudin $\mathrm{M}^{1}$, Juliandi $\mathrm{B}^{2}$, Boediono $\mathrm{A}^{1}$
}

\begin{abstract}
Conditioned medium has now gained increasing interest since the development of secretome-based therapy. Various types of cells have been studied as a source of the secretome. One of them is neural progenitor cells (NPCs). These are cells that capable of differentiating into neurons as well as glial cells. Indeed, the study on NPCs has risen in the last few decades, but the study on the differentiated cells has not clearly described. The most common procedures that widely used to get the conditioned medium is starvation. However, cell starvation may cause environmental stress and become an apoptotic trigger for the cells. In this study, we analyzed the effect of starvation on differentiated cells from E17 rat neural progenitor cells (NPCs) based on cells characteristics and secretome profile. We found that starvation decreased cells viability and affected the heterogeneity of the cell population. Astrocytes survived more under nutrient deprivation conditions, and the progenitor cells showed a higher tendency to differentiate to glial cells than neurons. Duration of starvation also influenced the secretome profile, alterations found in protein types and also their function in the biological process. During 24 hours of starvation, cells secreted proteins that were used to maintain cell growth, stimulate differentiation, and produce energy, but there were also proteins that identified and involved in autophagy activation. After 48 hours of starvation, astrocytes that became the dominant cells secreted proteins that try to keep protecting the remaining neurons.
\end{abstract}

Key Words: Conditioned médium; Differentiated cells; Neuron; Astrocytes; Secretome

\section{Introduction}

The use of secretome gained increasing attention since many researchers believed the paracrine hypothesis in which injecting cytokines, chemokines, or growth factor can cause significant repair or regeneration of injured tissues compared to implanting cells directly to the organs. Secretome can be obtained from conditioned medium of specific cells that released desired proteins.

One of the promising sources of secretome and being extensively investigated is neural progenitor cells (NPCs). These are cells that are capable of differentiating into neurons as well as glial cells and has been reported as an ideal tool to investigate neural cell differentiation, in vitro testing of neuroactive drugs, modelling neural diseases, or explore effective future cell-based therapies ${ }^{[1,2]}$. Moreover, NPCs not only can be used as a vast source of neuronal cells but also can secrete several growth factors and cytokine which widely used as secretome therapies instead of cells therapies in regenerative medicine ${ }^{[3,4,5]}$. Secretome-based therapy from both NPCs or MSCs reduces disease severity in animal model diseases such as inflammatory arthritis, Parkinson's disease, experimental traumatic brain injury, and myocardial infarction $^{[6-7]}$. In vitro studies also reported that secretome enhances the proliferative and migratory abilities of various types of cells ${ }^{[9,10]}$. However, how then the NPCs differentiate and do the differentiated cells of NPCs secrete certain proteins has not clearly described.
There are several methods to produce conditioned medium that contained secretome and to decipher its protein contents ${ }^{[1,12]}$. Unfortunately, serum supplemented media which is the most common media used in cell culture will give analytical challenges because of the masking effect of highly abundant serum proteins that caused secreted proteins analysis more complicated and extremely difficult. Whereas, proteomics studies is very important to delineate molecules and pathways critical for NSC biology and can answer questions about how NPCs or the differentiated cells can participate in neural repair ${ }^{[13]}$. Hence, serum deprivation is needed to overcome that problem.

However, serum deprivation, or also named as cell starvation, can also cause environmental stress and become an apoptotic trigger for the cells ${ }^{[14]}$. These conditions have been reported to influence cellular phenotypic characteristics, induce a swift and dynamic response, elicit complex and unpredictable time-dependent effects, and the cell-type dependent effect can interfere with the experimental results ${ }^{[15]}$.

In this study, we analyzed the effect of starvation on differentiated cells from E17 rat neural progenitor cells (NPCs) based on cells characteristics and secretome profile. We found that serum deprivation affected cells' viability, the pattern or tendency of differentiation, and secretome profile. Noteworthy is that the duration of starvation was very influential for differentiated cells of NPCs under serum deprivation culture conditions. 


\section{Materials and Methods}

Isolation and Culture of Differentiated Cells of Rat Neural Progenitor Cells (NPCs)

Wistar rat embryos (E17) were used in this study. Three replicated trials were carried out. The pregnant female rat was euthanized by intraperitoneal injection of ketamine-xylazine cocktail $(91 \mathrm{mg} / \mathrm{kg}$ ketamine $+9.1 \mathrm{mg} / \mathrm{kg}$ xylazine) $0.2 \mathrm{ml} / 100 \mathrm{~g}$ body weight. Uterus was exposed by medial cutting in aseptic condition to avoid contamination. All fetuses were removed and stored in sterile dissection solution (HBSS containing $0.3 \%$ glucose).

Whole brains were isolated and dissected into small pieces for the further digestion process. Dissected brain tissues were centrifuged at $300 \mathrm{xg}$ for 2 minutes, and the supernatant was discarded. Digestion process was done using Neural Tissue Dissociation Kit (T) (Miltenyi Biotec) based on manufacturer protocols. Cells then were cultured in 24 wells $0.1 \%$ gelatin coated dishes overnight at cell density $\left(5 \times 10^{4}\right.$ cells $/ \mathrm{cm}^{2}$ ). Medium used in this step was neurobasal medium (NM) MACS ${ }^{\circ}$ Neuro-Medium (Miltenyi Biotec) containing 2\% MACS NeuroBrew-21 (Miltenyi-Biotec), 1\% antibiotic-antimycotic (100x) (GibcoTM), 10\% fetal bovine serum (FBS; GibcoTM) and 1\% GlutaMax ${ }^{\circledR}$ (GibcoTM). The primary culture was done in 4 days and after that cells were characterized by flow cytometry and immunocytochemistry, being starved for 24 hours and 48 hours.

Experimental procedures of this research were approved by the Animal Care and Ethics Committee of National Institute of Health Research and Development, Ministry of Health, Republic of Indonesia (No: LB02.01/2/KE.150/2017).

\section{Cells Starvation and Conditioned Medium Collection}

After four days of primary culture, cells were cultured in serum-free condition by changing the medium with MEM medium (GibcoTM) without any supplement addition. After 24 hours, the conditioned medium (CM) was collected and changed with the fresh equilibrated medium. CM was collected again on the next 24 hours to identify secretomes which were secreted by differentiated cells from NPCs which had starved for 48 hours. Conditioned medium was collected from three replicates and then filtered using $0.22 \mu \mathrm{m}$ size of the pore and further used for secretome analysis. Trypan blue exclusion test was used for cells viability assay.

\section{Flowcytometry}

Differentiated cells of NPCs were characterized four days after culture before starvation treatment, 24 hours, and 48 hours starvation duration with PSANCAM-APC and A2B5-PE (Miltenyi Biotec). Staining steps were done following the instruction of the staining kit. Flowcytometry process and analysis were done using BD Accuri ${ }^{\mathrm{TM}}$ C6 Plus flow cytometer.

\section{Immunocytochemistry}

Besides being characterized by flow cytometry, cells were also characterized by immunocytochemistry with GFAP (Santa Cruz sc) and NeuN (Abcam ab104225) antibody markers. The secondary antibody used in this study was secondary HRP-conjugated antibody (Trekkie Universal Link, Starr Trek Universal HRP Detection Kit Biocare $\left({ }^{\circledR}\right)$. Staining procedures referred to the previous study by Rinendyaputri et al. ${ }^{[10]}$.

\section{Secretome Analysis}

The conditioned medium, which contained secretome from the differentiated cells of NPCs, were analyzed by LC/MS-MS. Protein concentration was determined by Bradford's method following the protocol of the User Guide Coomassie (Bradford) Protein Assay Kit and data was analyzed by Thermo SkanIt RE for Multisize GO software version 3.2. Protein from conditioned medium $(10 \mu \mathrm{g})$ proceeded for peptide preparation and in solution digestion using InSolution Tryptic Digestion and Guanidination Kit (Thermo Scientific).

Peptide clean up was done using Pierce C18 Spin Column (Thermo Scientific), the cleaned sample was then dried in a vacuum concentrator for 2 hours. The dried sample was then dissolved in $50 \mu l$ dissolving solution, $2.5 \mu l$ (500 $\mathrm{ng}$ peptides) and then continue to be fractionated. Fractionation results were analyzed using QExactive Mass Spectrometry (Thermo Scientific). Output data from LC-MS/MS were analyzed using Proteome Discoverer software 2.1 (Thermo Scientific) to identify proteins based on the Rattus norvegicus database (TaxonomyID: 10116) to identify the type of proteins from the conditioned medium. Gene ontology analysis was done using the protein analysis through evolutionary relationship (PANTHER) classification system site (http://pantherdb.org).

\section{Statistical Analysis}

Data evaluation was performed using one-way ANOVA to compare the mean values for the groups. The significance value was set at $\mathrm{p} \leq .05$. The results are presented as mean \pm SEM (standard error of the mean).

\section{Results}

\section{Cells Heterogeneity of Differentiated Cells of NPCs}

The expressions of surface markers of the differentiated cells of NPCs after four days culture was analyzed by flow cytometry using two markers, which are PSA-NCAM and A2B5. The results showed that there was heterogeneity of the differentiated cells that consisted

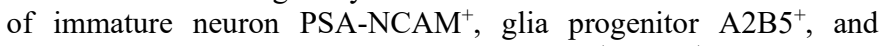
double positive of both markers $\left(\mathrm{PSA}^{+} \mathrm{NCAM}^{+} / \mathrm{A}_{2} \mathrm{~B}^{+}\right.$) as shown in Figure 1. Cells with PSA-NCAM ${ }^{+}$was the dominant cells in the population on the fourth day of the culture $(61.0 \pm 0.71 \%)$, A2B5 ${ }^{+}$ was $24.15 \pm 1,77 \%$, while cells with double positive expression were $14.05 \pm 2.62 \%$. The cells were then cultured in serum-free medium with low protein content for starvation treatment.

We found that the treatment altered heterogeneity profile of the cells culture after 48 hours of starvation. In detail, after 24 hours starvation, the percentage of two types of the cell population was decreased, but the alteration was not statistically significant, they were $52.6 \pm 4.24 \%$ for PSA-NCAM ${ }^{+}$and $12.6 \pm 0.29 \%$ for PSA$\mathrm{NCAM}^{+} / \mathrm{A} 2 \mathrm{~B} 5^{+}$. On the other hand, $\mathrm{A} 2 \mathrm{~B} 5^{+}$cells were increased $(33.55 \pm 3.47 \%)$, which still showed no significant difference. These patterns, the decrease of two types cells and the increase of $\mathrm{A}^{2} \mathrm{~B}^{+}$, were continued after 48 hours starvation. Cells with positive expression of A2B5 markers became the highest $(89.75 \pm 2.9 \%)$ while PSA-NCAM ${ }^{+}$greatly decreased $(3.75 \pm 1.2 \%)$ similar with the expression of double positive cells $(1.7 \pm 0.71 \%)$ (Figure 1$)$.

Heterogeneity profile alteration correlated with the viability of the cells. Duration of starvation for 24 hours decreased cells viability from $91.65 \pm 1.28 \%$ at four days culture into $90.5 \pm 0.3 \%$. The viability of the cells continued to decline with starvation duration; after 48 hours, starved cells viability was $83.82 \pm 0.89 \%$ (Figure 2).

Cells were stained with NeuN and GFAP to analyze differentiation that may cause heterogeneity profile of cultured cells, presented in Figure 3. Quantitatively, the results showed that after being isolated and cultured for 4 days, differentiation to be mature neuron (NeuN positive) or glial cells (GFAP cells) were $18.95 \pm 4.78$ for NeuN and $17.83 \pm 5.34$ for GFAP. GFAP positive cells were significantly increased after 48 hours starvation $(52.41 \pm 4.25)$ (Table 1). 


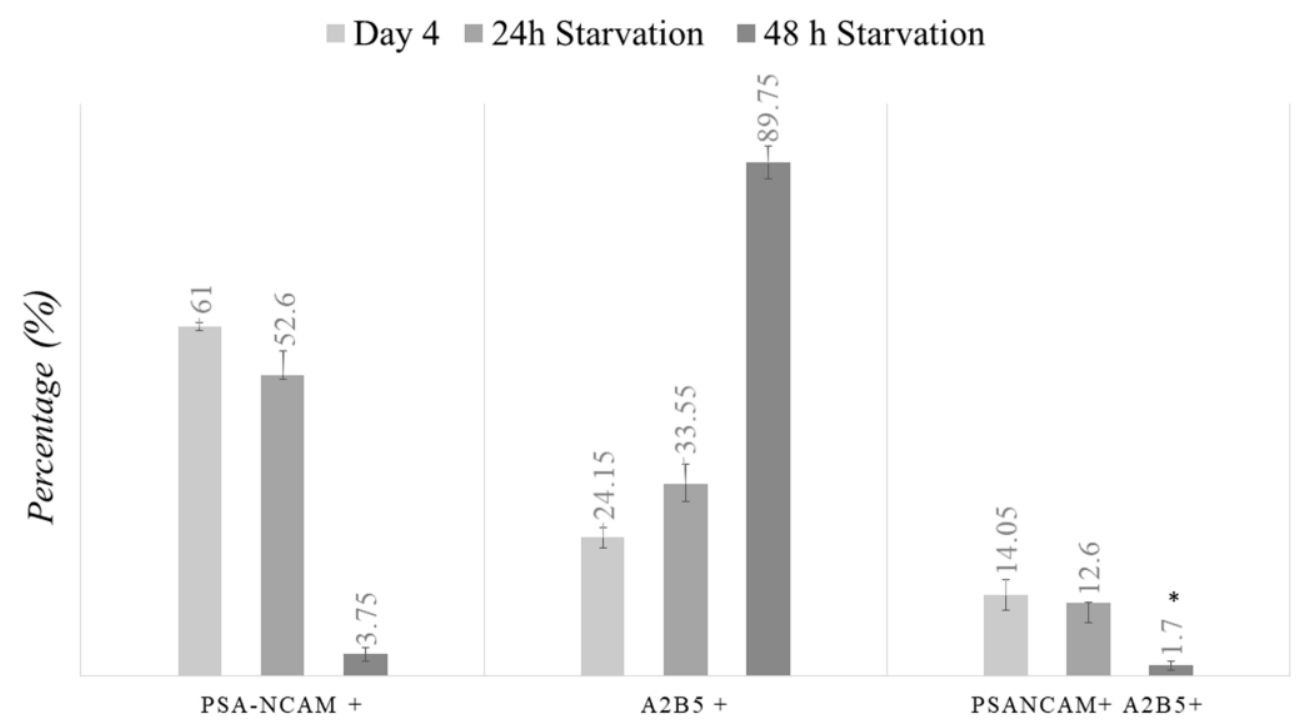

\section{Cells surface markers}

\section{(4)}

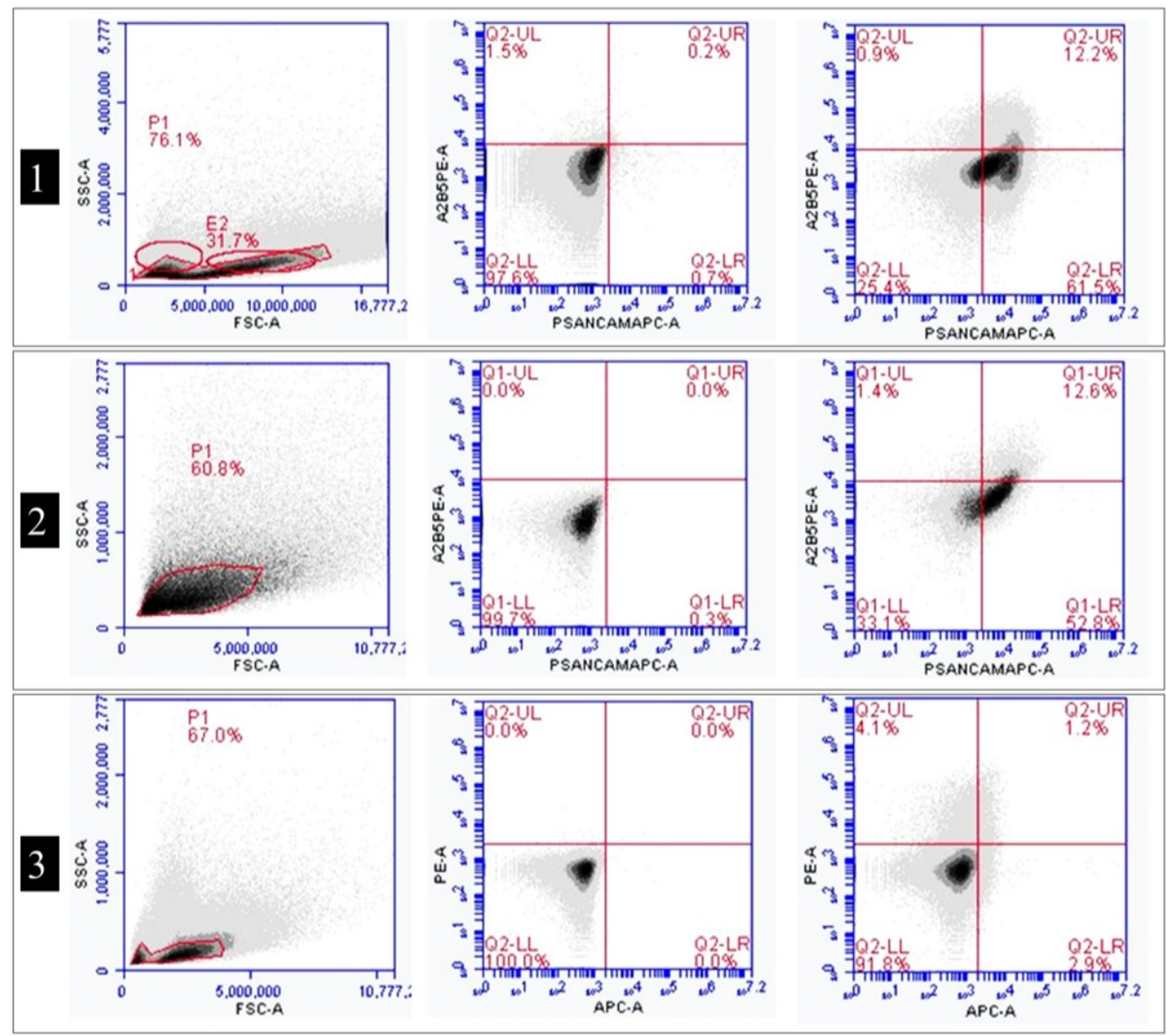

B

Figure 1 : Heterogeneity profile of Differentiated Cells of E17 Rat Neural Progenitor cells on day 4, 24 h and 48h after serum deprivation; (A) Percentage of PSA-NCAM+, A2B 5+, and double positive expression of both markers, presented as mean \pm SEM calculated from three replicates; (B) Flowcytometry results X axis : PSANCAM-APC; Y axis : A2B5-PE (cell population; isotype; cells immunophenotyping) on day 4 (1), 24 h after serum deprivation (2), and 48 h after serum deprivation. 


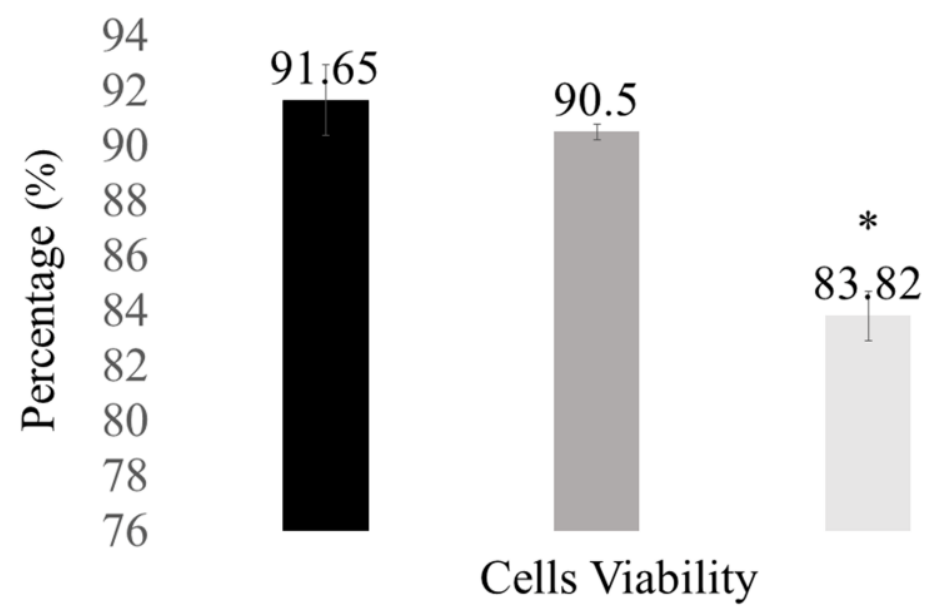

- Day $4 \backsim 24$ h starvation $\llbracket 48 \mathrm{~h}$ starvation

Figure 2: Viability of Differentiated Cells of E17 Rat Neural Progenitor Cells on Day 4, 24 Hours and 48 Hours After Serum Deprivation Culture

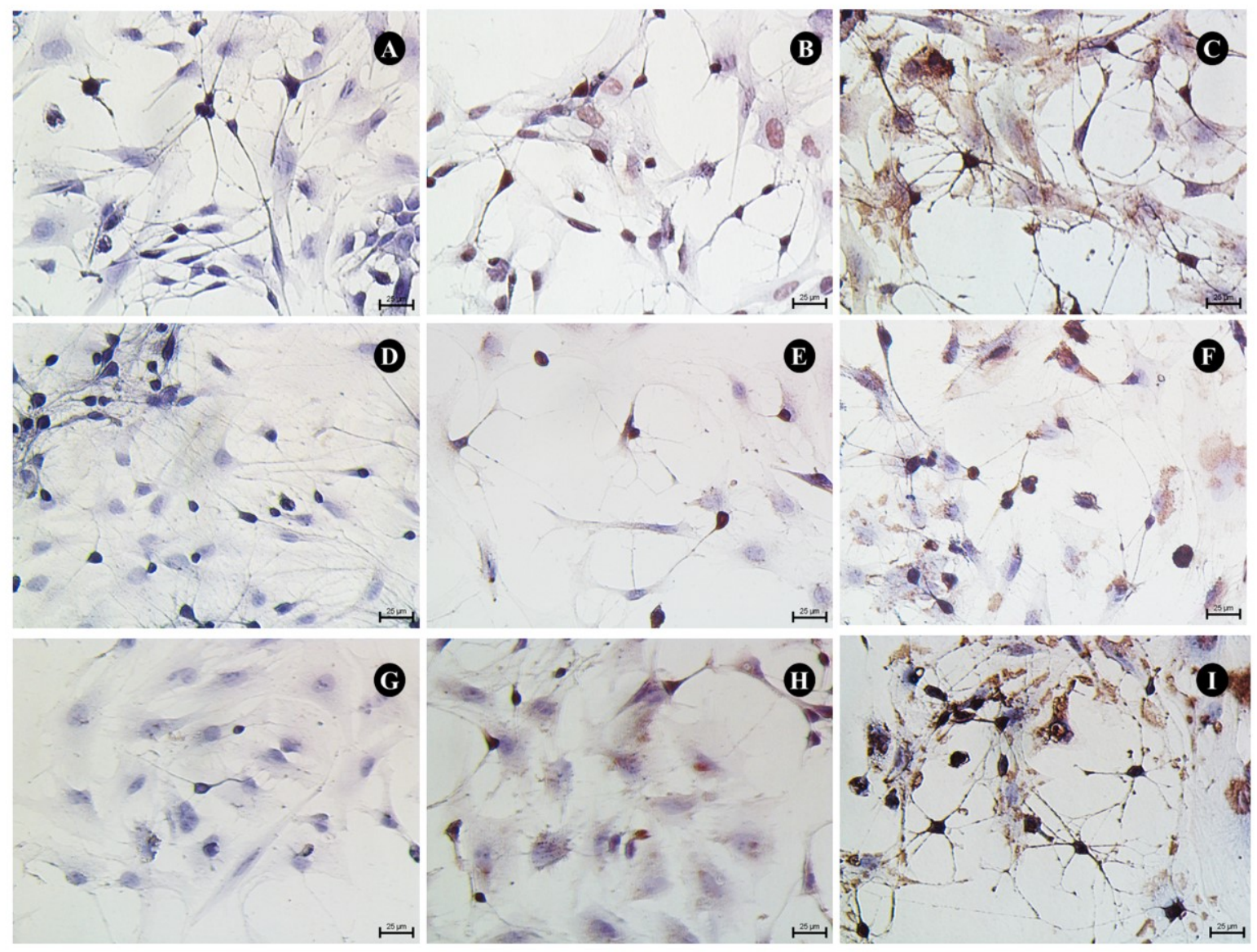

Figure 3: Immunocytochemisty of Differentiated Cells of E17 Rat Neural Progenitor Cells using NeuN and GFAP markers on Day 4 culture (A-C), 24 hours (D$F)$ and 48 hours After Serum Deprivation Culture (G-I); negative control $(A, D, G)$, NeuN Staining (B,E,H); GFAP Staining (C,F,I). Scale bars $=25 \mu$ m. 
Table 1. Assessment of Differentiation of E17 Rat Neural Progenitor cells by Immunocytochemistry Staining Using Neu-N and GFAP Markers on Day 4 culture, 24 hours and 48 hours

\section{After Starvation Culture}

\begin{tabular}{ccc} 
Culture experiment & \% Neu-N & \% GFAP \\
\hline Day 4 Primary Culture & $18.95 \pm 4.78^{\mathrm{a}}$ & $17.83 \pm 5.34^{\mathrm{a}}$ \\
\hline 24h Starvation & $27.04 \pm 3.12^{\mathrm{a}}$ & $22.07 \pm 3.44^{\mathrm{a}}$ \\
\hline 48h Starvation & $30.26 \pm 4.10^{\mathrm{b}}$ & $52.41 \pm 4.25^{\mathrm{b}}$ \\
\hline${ }^{*} \mathrm{a}, \mathrm{b}$ percentage of positive cells presented as mean \pm SEM; values with different letters within a column
\end{tabular}

\section{Secretome analysis}

Starvation did not only alter heterogeneity of the cells and affect the viability of the cells but also caused secretome changes in conditioned medium from differentiated cells of NPCs. There were 24 proteins (unique peptide $\geq 2$ and score sequest $H T>0$ ) identified from conditioned medium of differentiated cells of NPCs after 24 hours starvation (CM1) and 21 proteins from cells after 48 hours starvation (CM2) (Figure 4).

There were 15 identified proteins from CM1 and CM2. They were actin, keratin type II cytoskeletal 1, cystatin-C, keratin type II cytoskeletal 6A, peptidyl-prolyl-cis-trans-isomerase A, collagen alpha-1 (1) chain, sparc, stathmin, creatine kinase B-type, serum albumin, fructose-biphosphate aldolase A, 14-3-3 protein zeta/delta, collagen alpha 2 (1) chain, follistatin-related proteins, and collagen alpha 1 (1ll) chain. Proteins that were identified from CM1 were vimentin, tubulin alpha $1 \mathrm{~A}$, tubulin beta III, centrosomal protein of $162 \mathrm{kDa}$, heat shock cognate $71 \mathrm{kDa}, 14-3-3$ protein epsilon, fatty acid binding protein epidermal, pyruvate kinase PKM, and ubiquitin 40s ribosomal protein $\mathrm{s} 27 \mathrm{a}$. Six proteins were identified from CM2, superoxide dismutase, fibronectin, prosaposin, insulin-like growth factor binding proteins 2, apolipoproteins E, keratin type I cytoskeletal 10 (Figure 4).

Further analysis using gene ontology analysis (Figure 5) showed that alteration of protein types which were identified in CM1 and CM2 also related to protein function differences in cellular metabolism. Proteins that were identified from CM1 has three major molecular functions of protein binding, catalytic activity, and being structural molecules while proteins in CM2 played roles as molecular function regulator, transducer activity, and protein transporter. According to GO analysis, after 24 hours starvation, secreted proteins involved in biological processes, such as cellular component organization, cellular response, localization whereby a substance or cellular entity like protein complex is transported and or maintained in a specific location within a cell, and biological regulation. Meanwhile, after 48 hours of starvation, the proteins were more embroiled in the metabolic process. Results of the cellular component analysis revealed that proteins which were found in CM1 perform its molecular function in the cell, synapse, organelle, or as a protein complex while proteins in CM2 predominantly act in the extracellular region.
In terms of categorizing into a protein class, identified proteins in CM1 and CM2 can be classified into cell adhesion proteins, chaperones, cytoskeletal proteins, enzyme modulators, extracellular matrix proteins, oxidoreductases, signalling molecules, transfer proteins and transferases. Majority of proteins in CM1 were cytoskeletal and signalling molecules while in CM2 was enzyme modulators. Signaling pathway analysis showed that secreted proteins involved in pathways, such as cadherin, integrin, epidermal growth factor (EGF), fibroblast growth factor (FGF) and Wnt signalling pathways. On the other hand, proteins also were found to be associated in energy production through glycolysis and fructosegalactose metabolism. Besides, identified proteins may also stimulate apoptosis and inflammation mediated by chemokines and cytokines.

\section{Discussion}

Secretome-based therapy and in-depth study gained much attention since Mirotsou et al. reported that the paracrine factor was indeed responsible for beneficial effects than the cells themselves ${ }^{[8]}$. As reviewed by Vizoso et al., secretome as a cell-free therapy may resolve safety considerations, can be evaluated for dosage like other pharmaceutical agents, storage can be done without the application of potentially harmful cryopreservative chemicals, more economical, could be modified to desired cell-specific effects and there is possiblity for mass production ${ }^{[16]}$.

According to Beer et al., secretomes is the total of factors secreted by cells actively or passively. It can contain soluble proteins such as cytokines, chemokines, or growth factors and also can include lipid, free nucleic acid and extracellular vesicles ${ }^{[17]}$. Those factors can be obtained from the conditioned medium, the medium where cells are cultured $^{[3]}$. Mesenchymal stem cells are the common source to produce conditioned medium which contain secretome for a specific purpose $^{[16-19]}$. Meanwhile, another potential secretome source, especially for central nervous system diseases, is neural progenitor cells (NPCs). These cells are extensively investigated for their capacity to signal to the host upon transplantation in experimental neurodegenerative diseases which greatly increase day by day. Indeed, the study on NPCs has risen in the last few decades, but the studies on the differentiated cells have not still been clearly described. 


\begin{tabular}{|c|}
\hline CM 1 \\
\hline Vimentin \\
\hline Tubulin alpha 1A chain \\
\hline Tubulin beta-3 chain \\
\hline 14-3-3 protein epsilon \\
\hline $\begin{array}{c}\text { Centrosomal protein of } 162 \\
\text { kDa }\end{array}$ \\
\hline Pyruvate kinase \\
\hline Fatty acid binding protein \\
\hline $\begin{array}{c}\text { Heat shock cognate } 71 \text { kda } \\
\text { protein }\end{array}$ \\
\hline $\begin{array}{c}\text { Ubiquitin-40S ribosomal } \\
\text { protein S27a }\end{array}$ \\
\hline
\end{tabular}

\begin{tabular}{|c|}
\hline CM 1 \& CM 2 \\
\hline Cystatin c \\
\hline Sparc \\
\hline Stathmin \\
\hline Collagen alpha-1 (1) chain \\
\hline Collagen alpha-1 (ll1) chain \\
\hline Collagen alpha-2 (l) chain \\
\hline 14-3-3 protein zeta/delta \\
\hline Serum albumin \\
\hline Fructose-biphosphate aldolase A \\
\hline Creatine kinase B type \\
\hline Follistatin related protein 1 \\
\hline Peptidyl-prolyl cis-trans \\
isomerase A \\
\hline Actin, cytoplasmic 1 \\
\hline Keratin, type II cytoskeletal 1 \\
\hline Keratin, type II cytoskeletal 6A \\
\hline
\end{tabular}

\begin{tabular}{|c|}
\hline CM 2 \\
\hline $\begin{array}{c}\text { Insulin like growth factor } \\
\text { binding protein-2 }\end{array}$ \\
\hline Prosaposin \\
\hline Fibronectin \\
\hline Superoxide dismutase \\
\hline Apolipoprotein E \\
\hline Keratin type 1 cytoskeletal \\
10 \\
\hline
\end{tabular}

\section{CM1}

$\mathrm{CM} 2$

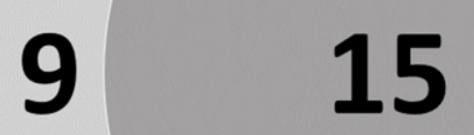

6 


\section{GO analysis of CM $1 \quad$ GO analysis of CM 2}

$\mathbf{A}$
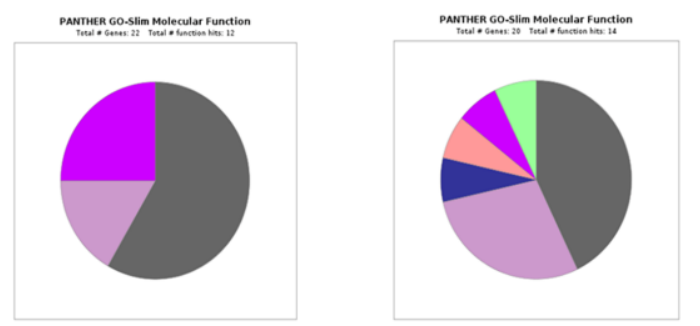

ainding (60:0005488) a

catalytic activity (G0:0003824) क

- molecular function requlator (60:0098772) a

molecular transducer activity (G0:0060089) a

- structural molecule activity (G0:0005198) a

transporter activity (G0:0005215) a

B
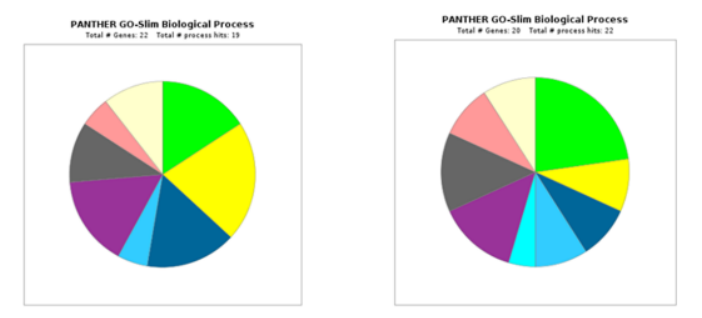

- biological requlation (60:0065007) a

Cellular component organization or biogenesis (60:0071840)

- cellular process (60:0009987) a

developmental process (60:0032502) a

arowth (60:0040007) a

- localization (GO:0051179)

metabolic process (60:0008152) a
multicellular oraanismal process (60:0032501) a

response to stimulus (60:0050896) a

C
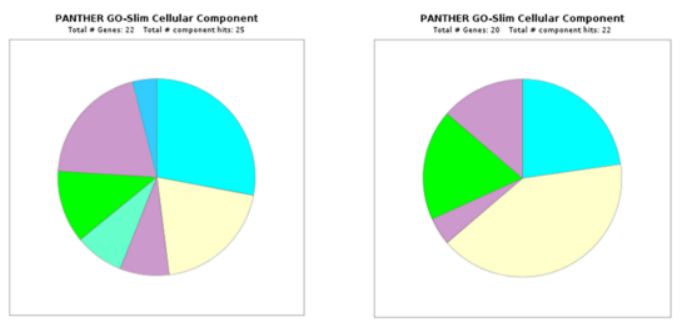

cell (GO:0005623) is

extracellular reqion (G0:0005576) a

membrane (G0:0016020) a

arqanelle (GO:0043226) a

protein-containina complex (G0:0032991) A

supramolecular complex (G0:0099080) a

synapse (60:0045202) a

D

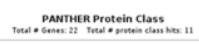
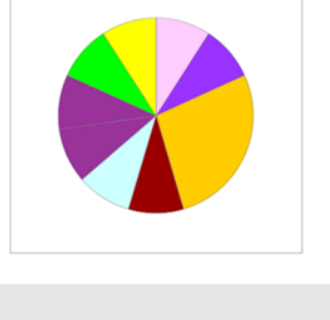

$\mathbf{E}$

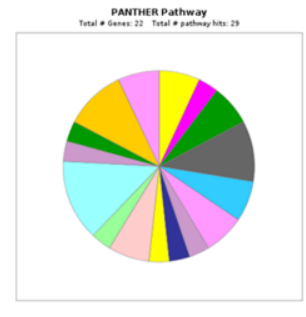

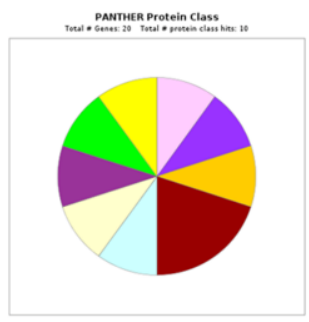

cell adhesion molecule (PCO0069). a

- chaperone (PC00072). a

cy cytoskeletal protein (PCO0085) a

- enzyme modulator (PC00095). is

extracellular matrix protein (PC00102). a

oxidoreductase $(\mathrm{PCO0176})$ a

signaling molecule ( $\mathrm{PCOO207)}$.

transfer/carrier protein (PCO0219). a

transferase (PCO0220). a

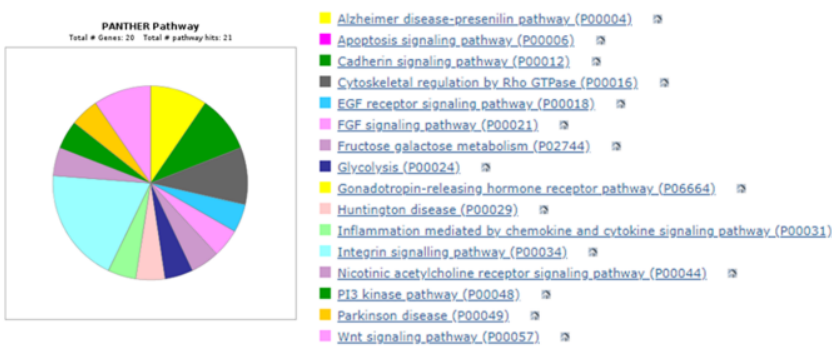

Figure 5: Pie chart of gene ontology (GO) analysis of proteins in CM1 (right) and CM2 (left). GO analysis consisted of molecular function (A), biological process $(B)$, cellular component $(C)$, protein class $(D)$, and signaling pathway of the identified proteins $(E)$ 
We isolated cells from the whole brain of E17 rat embryos and found that the cells were heterogeneous. Three types of cells were present, which are PSA-NCAM ${ }^{+}, \mathrm{A}_{2} \mathrm{B5}^{+}$, and cells that express both of these markers. Based on our results, after four days of culture, cells that were positive for PSA-NCAM marker was dominant. Polysialylated neural cell adhesion molecules are considered as one of the markers for immature neurons, developing and migrating neurons and neurons of synaptogenesis in the immature vertebrate nervous system. The results showed that the majority of the cells were immature neurons. Two other types of cells that can be identified are $\mathrm{A} 2 \mathrm{~B} 5^{+}$and cells that are not only positive for PSA-NCAM ${ }^{+}$but also for $\mathrm{A} 2 \mathrm{~B}^{+}$. Cells that express $\mathrm{A} 2 \mathrm{~B} 5^{+}$marker are considered to be bipotential glial precursor cells that have a capacity to give rise to oligodendrocytes and type- 2 astrocytes in vitro. These cells are also named glial restricted precursor cells (GRPs), which have a characteristic of being positive for A2B5 marker but do not express PSA-NCAM marker ${ }^{[20]}$. The last type cells identified by flow cytometry that were found to express both markers, according to Ben-Hur et al. are those cells of oligodendrocytes-type 2 astrocytes (O-2A) lineage which express positive for PSA-NCAM and can be detected in neonatal rat glial cell cultures ${ }^{[21]}$.

Majority of PSA-NCAM ${ }^{+}$cells representing immature neurons can be explained related to neurogenesis in the mammalian central nervous system. Neurons are generated primarily in the embryonic period, while most glial cells are generated after birth ${ }^{[22]}$. Neurogenesis of mouse or rat cerebral cortex commences around embryonic day 12 (E12), peaks at E15, and finishes around birth. Our findings showed that from E17 rat brains, immature neurons were the predominant cells, but there was also glial cells progenitor that can be obtained showing that gliogenesis at this time had been started. In murine, gliogenesis starts at E16 and continues to postnatal life ${ }^{[23]}$. According to Bandeira et al., changing numbers of neuronal and non-neuronal cells has an association with developmental stage neurogenesis and correlated with the brain growth ${ }^{[24]}$.

In the process to get secretome from the conditioned medium, cells are being cultured in serum-free conditions. Our study revealed that unfortunately, this step affects the cells themselves and the proteins identified in the conditioned medium.

Starvation of the cells was done by changing the medium with MEM medium, a basal medium which contains limited nutrition and without any addition of serum. During this serum deprivation, we found that the viability of the cells decreased significantly after 48 hours starvation. The decrease in the number of cells viability related to cell death process that can be classified based on morphological appearance into apoptotic, necrotic or autophagic ${ }^{[24]}$. Young et al. reported that nutrient deprivation could induce neuronal autophagy ${ }^{[25]}$. Autophagy activation is needed to clean misfolded proteins, decrease cytotoxicity, and prevent neurodegeneration.

Mura et al. reported that astrocytes showed a higher capability than neurons to cope with stress ${ }^{[26]}$. Previous studies proved that this type of glial cell was more able to cope with increased intracellular free $\mathrm{Zn}^{2+}$, are capable of counteracting stresses more effectively than neurons due to their antioxidant reserve, express a higher level of antioxidant enzymes than neuronal cells and are less vulnerable to ischemia than neurons ${ }^{[27,28]}$. In line with those studies, we found that neurons decreased in a time-dependent manner while astrocytes increased significantly as an indication that progenitor cells under starvation conditions will tend to differentiate into glial cells, especially astrocytes. Percentage of NeuN positive cells at four days culture, after 24 and 48 hours starvation were $18.95 \pm 4.78,27.04 \pm$ 3.12 , and $30.26 \pm 4.10$, respectively. On the other hand, the percentage of GFAP positive cells were $17.83 \pm 5.34,22.07 \pm 3.44$, and $52.41 \pm 4.25$, respectively, as shown in Table 1 and Figure 3.
This phenomenon is caused by the activation of Notch signaling. It prevents neuronal precursors from adopting neuronal fate; instead, it promotes the cells to irreversibly commit to glial fate. In the second step, Notch signaling would inhibit the differentiation of neuron and oligodendrocytes but promote the differentiation into astrocytes ${ }^{[29]}$.

Alterations and starvation also caused changes in the secretome profile that interpreted from protein identification in conditioned medium. During 24 hours of starvation, cells which were dominated by immature neurons, secreted proteins that are used to maintain cell growth, stimulate differentiation, and produce energy, but there were also proteins that were identified to be involved in stress responses and autophagy activation. After 48 hours of starvation, astrocytes that became the dominant cells, secreted proteins that try to keep protecting the remaining neurons.

We classified proteins found in CM1 into four groups, which are 'novel' extracellular proteins, microtubule organizing proteins, proteins involved in energy metabolism, stress and autophagic activation proteins. Vimentin was earlier known as an intracellular protein but then reported to be also secreted in the extracellular space showing novel protein activity ${ }^{[30]}$. Shigyo and Tohda reported that extracellular vimentin might be a novel neurotrophic factor that enhances axonal growth activity and motor function recovery after spinal cord injury ${ }^{[31]}$. Based on GO biological process, it correlated with cellular response to fibroblast growth factor signalling, was found to be involved in axonogenesis and cause positive regulation on glial proliferation. Proteins that involved in energy metabolism detected in CM1; pyruvate kinase, which is a glycolytic enzyme, and fatty acid binding protein that metabolizes lipid-derived source ${ }^{[32,33]}$. Although cells metabolized energy and keep releasing growth factors or proteins that were needed by the cells, under nutrient deprivation misfolded proteins could not be avoided. It urged the cells to activate lysosomal degradation and release stress protein. Ubiquitin and heat shock cognate proteins were two proteins that were found in CM 1 involved in those processes $^{[34,35]}$.

As the heterogeneity of cells altered after 48 hours starvation, with the dominance of glial and astrocytes cells, proteins that identified only in CM2 also were dominantly secreted by neuroglia cells. They were insulin-like growth factor binding protein, prosaposin, and fibronectin. Astrocytes also secreted a major cholesterol carrier apolipoprotein E.

Insulin-like binding protein will bind to an insulin-like growth factor that acts as neuroprotector to inhibit neuronal damage and enhances neuronal survival largely through the phosphoinositide 3 kinase (PI3k/Akt) signalling pathway ${ }^{[36]}$. Another protein, prosaposin, also has a neuroprotective and glioprotective effect when it binds to the $G$ protein-coupled protein GPR37 and GPR7L1 on their native environment, the astrocytes ${ }^{[37,38]}$. Besides, astrocytes also secreted fibronectin, one of the extracellular matrix molecules, that dynamically regulates neuronal function such as diffusion of neuroactive substances, receptor activation, and cell adhesion ${ }^{[39]}$. Remaining cells after 48 hours starvation also secreted apolipoprotein E that supports lipid transport and injury repair in the brain $^{[40]}$.

These results showed that alteration of cells heterogeneity affected the secretome profile. During a long time of nutrient deprivation, the survival rate of astrocytes and glial cells were higher than neurons. The external environment tends to give rise to different results in the neurogenesis process ${ }^{[41]}$. Nevertheless, astrocytes secreted proteins might still maintain the remaining neurons. These results revealed that astrocytes are not just 'glue' for structural support of the neuron but are also responsible for protecting neurons from environmental stress and undesired conditions. 
Gene ontology analysis was used to find out whether the differences of identified proteins in CM1 and CM2 affected the role of these proteins in terms of molecular function, biological process, cellular component, protein class, and signalling pathway. Based on the analysis, it was confirmed that not only the type of proteins changed, but also their function and biological process involvement.

\section{Conclusion}

Starvation of differentiated cells of NPCs decreased cells viability and caused heterogeneity alterations of the cell population. The cells showed a higher tendency to differentiate to glial cells and those glial cells, especially astrocytes, survived more under nutrient deprivation. The change of cells' composition in the population of the cells influenced the secretome profile. During 24 hours of starvation, cells secreted proteins that were used to maintain cell growth, stimulate differentiation, and produce energy, but there were also proteins that were identified to be involved in autophagy activation. After 48 hours of starvation, astrocytes became the dominant cells secreting proteins that try to keep protecting the remaining neurons.

\section{References}

1. Jády AG, Nagy ÁM, Köhidi T, Ferenczi S, Tretter L, Madarász E. Differentiation-dependent energy production and metabolite utilization: a comparative study on neural stem cells, neurons, and astrocytes. Stem Cells Dev. 2016;25(13):995-1005.

2. Walker T, Huang J, Young K. Neural stem and progenitor cells in nervous system function and therapy. Stem Cells Int. 2016;2016:12.

3. Pawitan JA. Prospect of stem cell conditioned medium in regenerative medicine. Biomed Res Int. 2014;2014:1-14.

4. Drago D, Cossetti C, Iraci N, Gaude E, Musco G, Bachi A, Pluchino S. The stem cell secretome and its role in brain repair. Biochimie. 2013;95(12):2271-85.

5. Dwijayanti A, Mubarok W, Boediono A, Purba JS, Purwaningsih EH, Suyatna FD. Brain derived neurotrophic factor levels in aged rats post-systemic human mesenchymal stem cell administration. Journal of SCRTE. 2018;2(2):29-32.

6. Kay AG, Long G, Tyler G, Stefan A, Broadfoot SJ, Piccinini AM, Middleton J, Kehoe O. Mesenchymal stem cell-conditioned medium reduces disease severity and immune responses in inflammatory arthritis. Sci Rep. 2017;7(1):1-11.

7. Mendes-Pinheiro B, Teixeira FG, Anjo SI, Manadas B, Behie LA, Salgado AJ. Secretome of undifferentiated neural progenitor cells induces histological and motor improvements in a rat model of Parkinson's disease. Stem Cells Transl Med. 2018;7(11):829-38.

8. Mirotsou M, Jayawardena TM, Schmeckpeper J, Gnecchi M, Dzau VJ. Paracrine mechanisms of stem cell reparative and regenerative actions in the heart. J Mol Cell Cardiol. 2011;50(2):280-9.

9. Park SR, Kim JW, Jun HS, Roh JY, Lee HY, Hong IS. Stem cell secretome and its effect on cellular mechanisms relevant to wound healing. Mol Ther. 2018;26(2):606-17.

10. Rinendyaputri R, Noviantari A, Budiariati V, Nikmah U, Zainuri M. The conditioned medium-rat bone marrow derived messenchymal stem cell (CM-RatBMMSC) can induce the differentiation ability of neural stem and progenitor cells (NPCs). Asian Jr. of Microbiol. Biotech. Env. Sc. 2018;20: S55-S61.

11. Dowling P, Clynes M. Conditioned media from cell lines: a complementary model to clinical specimens for the discovery of disease-specific biomarkers. Proteomics. 2011;11(4):794-804.

12. Stastna M, Van Eyk JE. Investigating the secretome lessons about the cells that comprise the heart. Circ Cardiovasc Genet. 2012;5(1):1-19.

13. Shoemaker LD, Kornblum HI. Neural Stem Cells (NSCs) and Proteomics. Mol Cell Proteomics. 2015;15(2):344-54.

14. Pirkmajer S, Chibalin AV. Serum starvation: caveat emptor. Am J Physiol Physiol. 2011;301(2):C272-9.
15. Codeluppi S, Gregory EN, Kjell J, Wigerblad G, Olson L, Svensson CI. Influence of rat substrain and growth conditions on the characteristics of primary cultures of adult rat spinal cord astrocytes. J Neurosci Methods. 2011;197(1):118-27.

16. Vizoso FJ, Eiro N, Cid S, Schneider J, Perez-Fernandez R. Mesenchymal stem cell secretome: Toward cell-free therapeutic strategies in regenerative medicine. Int J Mol Sci. 2017; 18(9): 1852.

17. Beer L, Mildner M, Ankersmit HJ. Cell secretome based drug substances in regenerative medicine: when regulatory affairs meet basic science. Ann Transl Med. 2017;5(7):170.

18. Teixeira FG, Carvalho MM, Sousa N, Salgado AJ. Mesenchymal stem cells secretome: A new paradigm for central nervous system regeneration? Cell Mol Life Sci. 2013;70(20):3871-82.

19. Assunção-Silva RC, Mendes-Pinheiro B, Patrício P, Behie LA, Teixeira FG, Pinto L, Salgado AJ. Exploiting the impact of the secretome of MSCs isolated from different tissue sources on neuronal differentiation and axonal growth. Biochimie. 2018;155:83-91.

20. Strathmann FG, Wang X, Mayer-Pröschel M. Identification of two novel glial-restricted cell populations in the embryonic telencephalon arising from unique origins. BMC Dev Biol. 2007;7:1-20.

21. Ben-Hur T, Rogister B, Murray K, Rougon G, Dubois-Dalcq M. Growth and Fate of PSA-NCAM+ Precursors of the Postnatal Brain. J Neurosci. 2018;18(15):5777-88.

22. Bandeira F, Lent R, Herculano-Houzel S. Changing numbers of neuronal and non-neuronal cells underlie postnatal brain growth in the rat. Proc Natl Acad Sci. 2009;106(33):14108-13.

23. Bergström $T$, Forsberg-Nilsson $K$. Neural stem cells: Brain building blocks and beyond. Ups J Med Sci. 2012;117(2):132-42.

24. G Kroemer, L Galluzzi1, P Vandenabeele, J Abrams, ES Alnemri, EH Baehrecke, MV Blagosklonny, WS El-Deiry, P Golstein, DR Green, M Hengartner, RA Knight, S Kumar, SA Lipton, W Malorni, G Nuñez, ME Peter, J Tschopp, J Yuan, M Piacentini, B Zhivotovsky. Classification of cell death: recommendations. Cell Death Differ. 2009;16(1):3-11.

25. Young JE, Martinez RA, La Spada AR. Nutrient deprivation induces neuronal autophagy and implicates reduced insulin signaling in neuroprotective autophagy activation. J Biol Chem. 2009;284(4):2363-73.

26. Mura E, Lepore G, Zedda M, Giua S, Farina V. Sheep primary astrocytes under starvation conditions express higher amount of LC3 II autophagy marker than neurons. Arch Ital Biol. 2014;152(1):47-56.

27. Schmuck G, Röhrdanz E, Tran-Thi QH, Kahl R, Schlüter G. Oxidative stress in rat cortical neurons and astrocytes induced by paraquat in vitro. Neurotox Res. 2002;4(1):1-13.

28. Gürer G, Gursoy-Ozdemir Y, Erdemli E, Can A, Dalkara T. Astrocytes are more resistant to focal cerebral ischemia than neurons and die by a delayed necrosis. Brain Pathol. 2009;19(4):630-41.

29. Grandbarbe L. Delta-Notch signaling controls the generation of neurons/glia from neural stem cells in a stepwise process. Development. 2003;130(7):1391-402.

30. Teshigawara K, Kuboyama T, Shigyo M, Nagata A, Sugimoto K, Matsuya Y, Tohda. A novel compound, denosomin, ameliorates spinal cord injury via axonal growth associated with astrocytesecreted vimentin. Br J Pharmacol. 2013;168(4):903-19.

31. Shigyo M, Tohda C. Extracellular vimentin is a novel axonal growth facilitator for functional recovery in spinal cord-injured mice. Sci Rep. 2016;6(June):1-9.

32. Lindsay KJ, Du J, Sloat SR, Contreras L, Linton JD, Turner SJ, Sadilek M, Satrustegui J, Hurley JB. Pyruvate kinase and aspartate-glutamate carrier distributions reveal key metabolic links between neurons and glia in retina. Proc Natl Acad Sci. 2014;111(43):15579-84.

33. Sakayori N, Kimura R, Osumi N. Impact of Lipid Nutrition on Neural Stem/Progenitor Cells. Stem Cells Int. 2013;2013:1-12. 
34. Yao TP. The role of ubiquitin in autophagy-dependent protein aggregate processing. Genes and Cancer. 2010;1(7):779-86.

35. Iftinca M, Flynn R, Basso L, Melo H, Aboushousha R, Taylor L, Altier C. The stress protein heat shock cognate 70 (Hsc 70) inhibits the Transient Receptor Potential Vanilloid type 1 (TRPV1) channel. Mol Pain. 2016;12:1-15.

36. Watanabe K, Uemura K, Asada M, Maesako M, Akiyama H, Shimohama S, Takahashi R, Kinoshita A. The participation of insulin-like growth factor-binding protein 3 released by astrocytes in the pathology of Alzheimer's disease. Mol Brain. 2015;8(1):114.

37. Meyer RC, Giddens MM, Schaefer SA, Hall RA. GPR37 and GPR37L1 are receptors for the neuroprotective and glioprotective factors prosaptide and prosaposin. Proc Natl Acad Sci. 2013;110(23):9529-34.
38. Liu B, Mosienko V, Vaccari Cardoso B, Prokudina D, Huentelman M, Teschemacher AG, Kasparov S. Glio- and neuroprotection by prosaposin is mediated by orphan G-protein coupled receptors GPR37L1 and GPR37. Glia. 2018;66(11):2414-26.

39. Wang JT, Yin L, Chen Z. Neuroprotective role of fibronectin in neuron-glial extrasynaptic transmission. Neural Regen Res. 2013;8(4):376-82.

40. Liu CC, Kanekiyo T, Xu H BG. Apolipoprotein E and Alxheimer disease: risk, mechanism and therapy. Nat Rev Neurol. 2013;9(2):106-18.

41. Ramli Y, Sulaiman A, Kurniawan M, Juliandi B, Wuyung PE. Intra-arterial Transplantation of Human Umbilical Cord Blood Mononuclear Cells in Sub-acute Ischemic Stroke Increases VEGF Expression in Rats. J. Stem Cells Regen. Med. 2018;14(2):69-79.

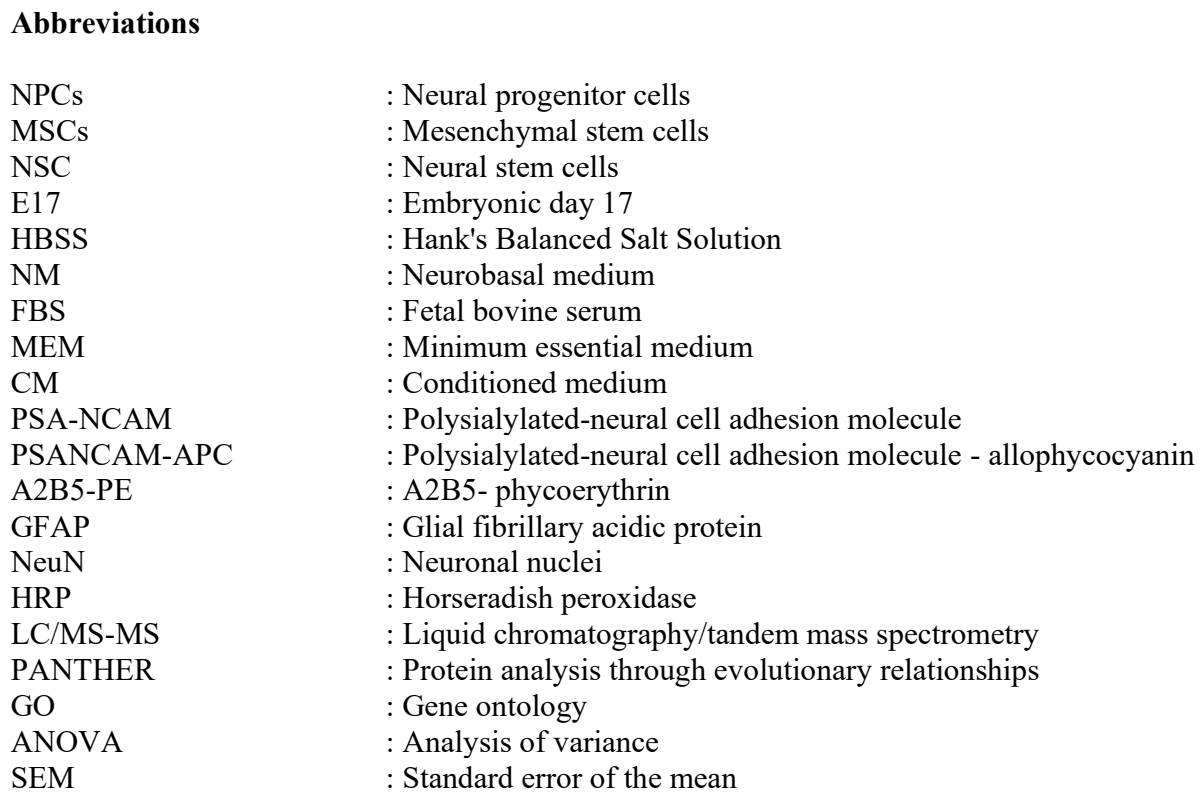

\section{Potential Conflicts of Interests}

There are no conflicts of interest to report.

\section{Sponsor/ Grants:}

This study was funded and supported by Directorate of Research and Community Service, Directorate General of Higher Education, Ministry of Research, Technology, and Higher Education, Republic of Indonesia through the PMDSU grant. The authors also would like to thank the National Institute of Health Research and Development, Ministry of Health, Indonesia and Dermama Proteomics Laboratory, for the supports and laboratory facilities.

\section{Corresponding Author}

Vista Budiariati; Department of Anatomy, Physiology, and Pharmacology, Faculty of Veterinary Medicine, IPB University, Jl. Agatis, Kampus IPB Dramaga, Bogor, Jawa Barat, 16680, Indonesia; E-mail: budi.vista@gmail.com; ab@apps.ipb.ac.id 